\title{
Metafísica y política en El nacimiento de la tragedia
}

\author{
José Emilio Esteban Enguita
}

\author{
Das tragische Kunstwerk. \\ Der tragische Mensch. \\ Der tragische Staat.
}

Nietzsche

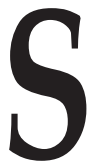

iempre es controvertido hablar de política en el caso de la obra de Nietzsche, e incluso es frecuente que se ponga en duda el que exista una dimensión política en su pensamiento que justifique una reflexión sobre tal dominio. De hecho, la mayor parte de la literatura secundaria a partir de los años cincuentas ha ignorado el problema de la política dentro de su filosofía, bien porque ha sido considerado irrelevante o marginal, bien porque se ha establecido la condición antipolítica de su pensamiento. Tal situación se debe en parte a la gran influencia que en el ámbito académico han tenido y siguen teniendo los trabajos sobre Nietzsche de M. Heidegger y W. Kaufmann. ${ }^{1}$ Por todo ello, a nuestro juicio es conveniente que antes de hablar sobre las ideas políticas de Nietzsche se justifique la existencia de un Nietzsche político, lo que supone mostrar tanto la necesidad de la política en su pensamiento como el lugar que ocupa en su interior. Centrándonos en $E l$ nacimiento de la tragedia, pretendemos aquí argumentar en favor de la ineludible presencia de la política en la obra de Nietzsche.

${ }^{1}$ De Heidegger, cuya interpretación nos muestra un Nietzsche apolítico dado que determina como inesencial todo aquello que no se atenga a lo "decisivo" de su pensar (vid. Martin Heidegger, Nietzsche, vol. I. Pfullingen, Neske, 1961, p. 16), a saber: el problema del ser. Han de mencionarse los siguientes textos sobre Nietzsche: "La frase de Nietzsche 'Dios ha muerto'”, en Holzwege. Fráncfort del Meno, Klostermann, 1950; "Quién es el Zaratustra de Nietzsche?", en Vörtrage und Aufsätze. Pfullingen, Neske, 1954, y la primera parte de Wass heisst Denken? Tubinga, Niemeyer, 1954. El trabajo principal de Walter Kaufmann sobre Nietzsche es Nietzsche. Philosopher, Psychologist and Antichrist. 4a. ed. Princenton/Londres, Universidad de Princenton, 1974. Una de las tesis principales de su libro sostiene que todas las críticas políticas vertidas por Nietzsche se hacen desde una perspectiva cultural y sustancialmente antipolítica (vid. Walter Kaufmann, op. cit., p. 412). 


\section{Metafísica y tragedia: el substrato ontológico de la visión dionisiaca del mundo}

En su violenta y en ocasiones panfletaria polémica con David Strauss, Nietzsche le critica, entre otras muchas cosas, por su incapacidad para construir un buen libro, por la ausencia de la "fuerza artística" necesaria para elaborar la arquitectura que requiere todo texto de calidad, por no poseer aquella facultad intuitiva que capta la totalidad y, por tanto, por no poder trazarla y no diseñar correctamente las partes que la componen, sus relaciones y sus posiciones respecto al todo. ${ }^{2}$ No son éstos los reproches que se pueden lanzar contra El nacimiento de la tragedia, sino precisamente los contrarios, aquellos que surgen de una potencia artística tan poderosa que, de no ser controlada, acaba devorando la riqueza y la complejidad de los fenómenos y sus relaciones, pues expulsa de ellos todo aquello que no sirve para ejemplificar la Idea concebida a partir de la vivencia dionisiaca. Respecto a los problemas que nos plantea la tragedia griega, Kaufmann señala la pobreza de la interpretación mantenida en El nacimiento de la tragedia. ${ }^{3}$ Pero no hace falta ir tan lejos: en su Ensayo de autocrítica,${ }^{4}$ escrito en 1886 y añadido a El nacimiento de la tragedia, es el propio Nietzsche quien indica los errores que por fuerza debe cometer aquel que se considera un iniciado en la sabiduría de los misterios, un discípulo de un dios que habla a los suyos y que se encuentra apresado por el convencimiento que su fe le proporciona, que, por supuesto, le exime del inútil trabajo de "dar demostraciones". ${ }^{5}$ La interpretación metafísica que contiene la visión dionisiaca del mundo, pilar sobre el que se sostiene El nacimiento de la tragedia, puede ser $-\mathrm{y}$, de hecho, lo es- tan arbitraria y ajena en relación con los fenómenos que pretende explicar como cualquier otra "visión del mundo". El valor de su primera obra, como el propio Nietzsche indica en su Ensayo de autocrítica, está en el problema que plantea, en la interrogación sobre lo dionisiaco que saca a la luz por primera vez, ${ }^{6}$ y no en las soluciones aportadas por una "metafísica del artista" dudosa

\footnotetext{
${ }^{2}$ Friedrich Nietzsche, "Unzeitgemässe Betrachtungen", en Sämtliche Werke. Kritischen Studienausgabe (KSA) in 15 Einzelnbänden. Herausgegeben von Giorgio Colli und Mazzino Montinari. Berlin/New York, Deutscher Taschenbuch Verlag/Walter de Gruyter, 1967-77 und 1980, vol. I, pp. 208 y ss.

3 Walter Kaufmann, Tragedia y filosofía. Trad. de Salvador Oliva. Barcelona/ Caracas/México, Seix Barral, 1978, p. 300.

${ }^{4}$ F. Nietzsche, El nacimiento de la tragedia. Introd., trad. y notas de Andrés Sánchez Pascual. Madrid, Alianza, 1973, pp. 25-37 ["Die Geburt der Tragödie", en Sämtliche Werke, vol. I, pp. 11-22].

${ }^{5}$ Ibid., p. 28 [p. 14].

${ }^{6}$ Ibid., p. 35 [p. 20].
} 
en sí misma y calificada posteriormente por Nietzsche como "arbitraria, ociosa, fantasmagórica". 7

Así como Schopenhauer, en el "Prólogo" a la primera edición de El mundo como voluntad y representación, aconsejó al lector, indicándole de qué forma debería leerlo si quisiera entenderlo, de la misma manera tendría que haber procedido Nietzsche, pues su obra El nacimiento de la tragedia, en lo que respecta a su estructura, es semejante a aquella obra de su "maestro", quien sobre su texto nos dice lo siguiente:

En cambio, un único pensamiento, por amplio que pueda ser, tiene que mantener la más perfecta unidad. Sin embargo, si con el fin de su exposición se deja dividir en partes, la relación entre ellas tiene que ser orgánica, es decir, de tal modo que cada parte sostenga el todo en la misma medida en que es sostenida por él, que ninguna sea la primera ni la última, que el pensamiento en su totalidad obtenga claridad a través de cada parte y que también la parte más pequeña no pueda llegar a comprenderse sin que antes lo sea el todo. ${ }^{8}$

Pero a diferencia de El mundo como voluntad y representación, en que cada parte o aspecto de ese único pensamiento está claramente delimitado y desarrollado hasta sus últimas consecuencias, El nacimiento de la tragedia no se caracteriza por esa voluntad de pureza lógica, ya que los momentos de la Idea que constituye su núcleo forman una madeja difícil de deshacer debido a que se solapan unos con otros, se mezclan en muchos parágrafos, se interrumpen para ser continuados después, no se delimitan con precisión y bastantes de ellos están poco o prácticamente nada desarrollados. A pesar de ello, se distinguen dos partes en la secuencia de parágrafos que componen $E l$ nacimiento de la tragedia que, si bien contienen, entremezclados, los niveles en los que se desenvuelve el fondo metafísico de la obra, sitúan los problemas en dos momentos temporales distintos: el pasado griego y el presente alemán. De un modo análogo a la tragedia de la que habla, la estructura de su obra se organiza a partir de dos dimensiones heterogéneas: el ideal griego, puesto como arquetipo que debe ser recreado e incluso superado, elevándolo a un nivel superior, ${ }^{9}$ y el diagnóstico sobre la situación de Alemania en

${ }^{7}$ Ibid., pp. 31-32 [p. 17]. Zaratustra, el alter ego de Nietzsche, critica el tiempo en el que formó parte de los transmundanos, cuando pensó el mundo como creación de un dios sufriente y contradictorio. (Vid. F. Nietzsche, "Also sprach Zarathustra", en Sämtliche Werke, vol. IV, p. 35.)

${ }^{8}$ Arthur Schopenhauer, "Die Welt als Wille und Vorstellung", en Sämtliche Werke. Wiesbaden, Eberhard Brockhaus Verlag, 1972, vol. II, p. VIII.

${ }^{9}$ En El nacimiento de la tragedia, Nietzsche afirma repetidas veces, con un entu- 
su tiempo, "juicio histórico" que tiene como criterio de valoración la oposición entre la cultura socrática o alejandrina, hegemónica en todo el mundo moderno, ${ }^{10}$ y la cultura trágica, vencida por la anterior pero superior en todos los sentidos, en cuyo renacimiento alemán tiene Nietzsche puesta su fe. ${ }^{11} \mathrm{Y}$ el nexo entre ambas partes, así como la justificación de cada una de ellas, se encuentra en esa "metafísica del artista" que expresa la Idea del Mundo, de la que se derivarán todas las demás consideraciones sobre los dominios particulares (lógica, historia, moral, política, estética, etcétera), las cuales, en el caso que nos concierne, no poseen la cualidad de consecuencias extraídas de premisas que funcionan como principios, sino de interpretaciones que funcionan, dentro de un todo orgánico, ${ }^{12}$ como desarrollos de un único sentido aprehendido en la Idea.

Cuando en su meritoria biografía sobre Nietzsche, C. P. Janz, a propósito de El nacimiento de la tragedia, observa que es característico de toda la obra y del talante de Nietzsche "la referencia inmediata a la Antigüedad sin escalones intermedios, y al revés, el salto de la Antigüedad a su presente, también sin escalones intermedios", ${ }^{13}$ tiene razón, aunque esto no es lo decisivo en el pensamiento del filósofo. Lo fundamental son los criterios filosóficos que subyacen en la comparación entre los griegos y los modernos, los cuales en ningún caso son los mismos en el conjunto de las obras de Nietzsche. En $E l$

siasmo muy poco "científico", la naturaleza paradigmática del pueblo y la cultura griega: comparados con otros pueblos, pretenden tener $-\mathrm{y}$ Nietzsche no duda que lo hayan conseguido- "la dignidad y la posición especial que al genio le corresponde entre la masa" (F. Nietzsche, El nacimiento de la tragedia, p. 126 ["Die Geburt der Tragödie", en op. cit., vol. I, p. 97]); no sólo son los mejores, los tipos más elevados de hombres que han existido, sino que, además, en su calidad de "fundadores", "tienen en sus manos, como aurigas, tanto nuestra cultura como cualquier otra" (ibid., p. 126 [p. 98]); por todo ello, de estos "maestros supremos" (ibid., p. 160 [p. 129]), de este pueblo, "es lícito decir que el poder aprender de él constituye ya una alta gloria y una rareza que honra" (ibid., pp. 159-160 [p. 129]). Un aforismo del año 1869 resume espléndidamente el valor supremo que otorga Nietzsche a lo griego: "Lo griego tiene para nosotros el mismo valor que lo sagrado para los católicos" (F. Nietzsche, "Nachgelassene Fragmente", en Sämtliche Werke, vol. VII, 1[29], p. 18. Traducción mía).

${ }^{10} \mathrm{~F}$. Nietzsche, El nacimiento de la tragedia, p.146 ["Die Geburt der Tragödie", en op. cit., vol. I, p. 116].

${ }^{11}$ En varios lugares de El nacimiento de la tragedia nos expresa Nietzsche su convicción: ibid., pp. 131-132, 163-164, 180-181 y 189 [pp. 102-103, 131-132, 146-147 y 153-154].

${ }^{12}$ Un excelente análisis sobre el significado que tiene el concepto de "todo orgánico" en El nacimiento de la tragedia se encuentra en Robert E. McGinn, "Culture as Prophylactic: Nietzsche's Birth of Tragedy as Culture Criticism", en Nietzsche-Studien, Band 4, 1975, pp. 114 y ss.

${ }^{13}$ Curt Paul Janz, Friedrich Nietzsche. Trad. de Jacobo Muñoz e Isidoro Reguera. Madrid, Alianza, 1987, vol. II, p. 131. 
nacimiento de la tragedia esta comparación no sólo está presente; es, además, el pilar central sobre el que se edifica su obra, la clave de su estructura. Y, a su vez, la comparación, en este caso, descansa sobre los cimientos construidos por una metafísica.

¿Cuál es la Idea que constituye el principio bajo el que se ordena $\mathrm{El} \mathrm{naci-}$ miento de la tragedia? ¿Existe, en realidad, una única Idea que confiere unidad a la multiplicidad de aspectos, de temas, de problemas que presenta esta obra? Pensamos que la respuesta más clara a estas dos preguntas nos la ofrece Nietzsche en la interpretación que tiene de su primera obra en Ecce Homo: "Una 'idea' -la antítesis dionisiaco y apolíneo-, traducida a lo metafísico; la historia misma, como el desenvolvimiento de esa 'idea'; en la tragedia, la antítesis superada en unidad". ${ }^{14}$

Importa poco aquí cuál fue el "contexto de descubrimiento" por el que Nietzsche llegó a esta idea; ${ }^{15}$ lo decisivo es su existencia y la función de principio que desempeña en esta obra temprana. Además, tampoco es necesario acudir a otros textos para apoyar esta interpretación: el mismo desarrollo de El nacimiento de la tragedia exige un substrato ontológico, la dualidad Voluntad-apariencia, si queremos encontrar la razón de las oposiciones en los diferentes niveles en los que se despliega el texto y, sobre todo, la razón que permite justificar lógicamente lo que se podría calificar "la unión trágica de los opuestos". Incluso tal idea es formulada inequívocamente en el texto, cuando en el parágrafo cuarto Nietzsche expone la "conjetura metafísica" a la cual, debido a la contemplación de los omnipotentes instintos artísticos de la naturaleza y a su anhelo ferviente de apariencia, se siente empujado, a saber: "que lo verdaderamente existente, lo Uno primordial, necesita a la vez, en cuanto es lo eternamente sufriente y contradictorio, para su permanente redención, la visión extasiante, la apariencia placentera". ${ }^{16}$

${ }^{14}$ F. Nietzsche, Ecce Homo. Introd., trad. y notas de Andrés Sánchez Pascual. Madrid, Alianza, 1971, p. 68 ["Ecce Homo", en Sämtliche Werke, vol. vI, p. 310].

${ }^{15}$ Siendo en general correcta la autointerpretación que Nietzsche hace en Ecce Homo, hay un detalle que, en nuestra opinión, no es exacto: la "idea", es decir, la antítesis apolíneo-dionisiaca, no es alcanzada por Nietzsche a partir del conocimiento filológico de la cultura griega, convirtiéndola, desde aquí, en una construcción metafísica; por el contrario, es el conocimiento de la filosofía de Schopenhauer el que proporciona a Nietzsche un marco teórico que utiliza para interpretar la oposición Apolo-Dioniso tanto en el teatro como en el culto griego. La reelaboración que hace Nietzsche de la filosofía de Schopenhauer es, en cierto modo, el a priori en el que encaja y soluciona el rompecabezas griego. Por ello, hay que enfrentarse a $E l$ nacimiento de la tragedia desde una perspectiva eminentemente filosófica y sólo secundariamente filológica.

${ }^{16}$ F. Nietzsche, El nacimiento de la tragedia, p. 57 ["Die Geburt der Tragödie", en op. cit., vol. I, p. 38]. 


\section{Tragedia y política: lugar y necesidad de la política en la visión dionisiaca del mundo}

Señalada la Idea que sostiene el conjunto desordenado de aspectos que aparecen en El nacimiento de la tragedia, y considerada como aquella que engloba a todo lo demás, sin lo que ese "todo lo demás" no puede ser adecuadamente comprendido, hemos cumplido el requisito para abordar el problema que nos interesa de esta obra: su pensamiento político. Éste, insinuado en lugares distintos, nunca desarrollado suficientemente, brotando siempre de un modo indirecto por breves momentos en lugares que parecen ocupar zonas muy marginales y surgiendo dentro de diversos contextos ajenos a las consideraciones de orden político, requiere una reconstrucción por parte del intérprete que ha de apoyarse no solamente en el texto, sino también en los Póstumos de la época que mantienen una relación directa e inequívoca con las pinceladas impresionistas que contiene El nacimiento de la tragedia sobre esta cuestión. Esta reconstrucción no tiene como finalidad proporcionar una exposición sistemática de la teoría política de Nietzsche, ya que cualquier acercamiento sistemático implicaría decir mucho más de los problemas políticos de lo que el propio Nietzsche dijo. El sentido de lo que denominamos "reconstrucción" es el de localizar el espacio que lo político ocupa en este libro de Nietzsche, así como valorar su relación con otros aspectos y, sobre todo, determinar la necesidad de un espacio tal en la obra de este filósofo. Además, basar la interpretación no sólo en El nacimiento de la tragedia, sino también en los Póstumos que remiten a tal obra, es a nuestro parecer algo obligado, porque en estos fragmentos y escritos se encuentra una exposición mucho más detallada y reveladora de los trazos poco definidos que aparecen en El nacimiento de la tragedia sobre las cuestiones políticas. ${ }^{17}$

Las diversas observaciones políticas, diseminadas aquí y allá, van a estructurarse atendiendo a su vínculo interno y necesario con la noción fundamental de El nacimiento de la tragedia, la de tragedia.

La tragedia es uno de los "inventos" griegos que han marcado la singularidad y la influencia de este pueblo ante los ojos y el pensamiento de la posteridad occidental. A esto hay que añadir la complejidad que encierra tal creación humana. Como núcleo de lo que Nietzsche denomina "cultura trá-

${ }^{17}$ Una lectura del fragmento más importante sobre este problema, titulado Fragment einer erweiterten Form der Geburt der Trägodie (F. Nietzsche, "Nachgelassene Fragmente", en op. cit., vol. VII, 10(1), pp. 333-349), y del Prólogo Der griechische Staat (F. Nietzsche, "NS", en Sämtliche Werke, vol. I, pp. 764-777), en el escrito póstumo Fünf Vorreden zu fünf ungeschriebenen Büchern, es suficiente para confirmar esta valoración de la obra póstuma. 
gica”, ${ }^{18}$ este fenómeno reúne diversas dimensiones y alcanza la categoría de "totalidad": el hombre y el ser quedan anudados de un determinado modo en la tragische Kunstwerk. La tragedia es una totalidad porque su significado principal consiste en una correspondencia ontológica entre el ser (el enigmático "Uno primordial"), interpretado como Voluntad artista, y una Daseinform, una forma de existencia humana que es parte del dominio de la apariencia. En la tragedia, en el espectáculo del hombre trágico, la Voluntad alcanza la meta común de los instintos apolíneo y dionisiaco, ${ }^{19}$ hecho que sólo puede comprenderse como la consecución del mayor grado de satisfacción en la apariencia y por consiguiente como su redención más acabada. Por otro lado, desde el punto de vista de la apariencia, que no es más que la visión extasiante de lo Uno primordial, eternamente sufriente y eternamente contradictorio, el hombre trágico (o su forma más elevada, el genio trágico) es el instrumento del designio artístico de la Voluntad.$^{20}$ Fundido con ella, con el único sujeto artístico verdadero, en el acto de creación artística, el hombre trágico consigue la reconciliación entre Apolo y Dioniso, es decir, la tragedia, "la manifestación apolínea sensible de conocimientos y efectos dionisiacos" ${ }^{21} \mathrm{o}$, dicho con otras palabras, la "redención y transfiguración del mundo". ${ }^{22}$ Esta apariencia en que consiste el hombre trágico es una forma de vida superior respecto a otras formas de vida no sólo porque consuma la meta del ser, sino porque, como obra de arte autoconsciente, posee la verdadera sabiduría -la dionisiaca. Sabe que "Todo es Uno" y que el sufrimiento es el núcleo más íntimo del mundo; afirma, a pesar de todo, la existencia en virtud de su fortaleza, del conocimiento metafísico que le consuela -con él puede ver que "bajo el torbellino de los fenómenos continúa fluyendo indestructible la vida eterna" $-{ }^{23}$ y del arte, esa transfiguración

${ }^{18}$ F. Nietzsche, El nacimiento de la tragedia, p. 145 ["Die Geburt der Tragödie", en op. cit., vol. I, p. 116]. Hay que advertir que siempre que utilicemos la palabra "cultura", nos estamos refiriendo a Kultur; Bildung se traducirá por "formación", haciendo notar que en castellano esta palabra no satisface la riqueza significativa del término alemán. Por fuerza hay que utilizar alguna palabra, aunque en nuestro idioma ninguna sea equivalente a Bildung. En todo caso, el significado de ambas palabras en alemán es distinto y, desde luego, en Nietzsche lo es. Por ello hay que usar en nuestra lengua dos palabras diferentes o, al menos, especificar en qué sentido utilizamos la palabra "cultura", dado que de esta forma se suele traducir indistintamente Kultur y Bildung. Así lo hace casi siempre Andrés Sánchez Pascual en su excelente traducción de El nacimiento de la tragedia, incurriendo, en nuestra opinión, en una importante imprecisión.

${ }^{19}$ Ibid., p. 61 [p. 42].

${ }^{20}$ Ibid., p. 85 [p. 47].

${ }^{21}$ Ibid., p. 85 [p. 62].

22 Ibid., p. 48 [p. 32].

${ }^{23}$ Ibid., p. 145 [p. 115]. 
mágica del horror insoportable que produce el conocimiento, único mago que "es capaz de retorcer esos pensamientos de náusea sobre lo espantoso o absurdo de la existencia convirtiéndolos en representaciones con las que se puede vivir". ${ }^{24}$

Siendo este sentido metafísico de la tragedia el principal, en cuanto constituye el substrato sobre el que se sostendrán todas las piezas que componen la tragedia. La obra de arte trágica, además, supera sin ningún género de dudas el ámbito estrecho de lo que se puede concebir como "literatura", abarcando todos los órdenes en los que se manifiesta la existencia humana: el pensamiento, la moral, la religión... y, por supuesto, la política, los asuntos concernientes a la polis o a la politeia (Constitución), todo aquello relativo a lo que Nietzsche denomina "Estado". Con esto no queremos decir que el significado de la tragedia sea otro que el puramente "estético", es decir, metafísico. Ante este milagroso acto de la "voluntad helénica", centenares de pensadores, comenzando por Aristóteles, se han descarriado al no ver en ella la unión de las dos potencias artísticas antagónicas, no cansándose "de proclamar que lo auténticamente trágico es la lucha del héroe con el destino, la victoria del orden moral del mundo, o una descarga de los afectos operada por la tragedia". ${ }^{25}$ No sólo de la tragedia, sino del arte en general, no se debe decir nada ni debe atribuirsele otra finalidad que no sea estética: siendo el arte la "actividad propiamente metafísica del hombre" ${ }^{26}$ no puede consistir en otra cosa que en el juego placentero de la Voluntad consigo misma, ${ }^{27}$ frente a lo cual todo lo demás, incluso los hombres artistas, carece de importancia. Y desde luego mucho más ajeno al dominio del arte que el resto de las cosas se encuentra, si cabe, lo concerniente a la política. La tragedia, en la medida que su fundamento es lo dionisiaco, y la política o los "instintos políticos", no sólo ocupan dos esferas distintas sino que mantienen una relación de indiferencia e, incluso, de hostilidad. ${ }^{28}$ Nietzsche deja suficientemente clara la separación de ambos dominios cuando considera errónea la explicación política del coro: éste no puede representar la lucha política entre el pueblo y el príncipe, ni la inmutable ley moral de los demócratas atenienses, ni es el presentimiento de una representación constitucional del pueblo, porque, en primer lugar, de los orígenes puramente religiosos del coro "está excluida toda antítesis entre pueblo y príncipe, y, en general, cualquiera esfera político-social"; 29 y, en segundo lugar, porque en la forma clásica del coro en Esquilo y Sófocles es

\footnotetext{
${ }^{24}$ Ibid., pp. $78-79$ [p. 57]

${ }^{25}$ Ibid., p. 175 [p. 142].

${ }^{26}$ Ibid., p. 31 [p. 17].

${ }^{27}$ Ibid., p. 188 [p. 152].

${ }^{28}$ Ibid., p. 166 [p. 133].

${ }^{29}$ Ibid., p. 74 [p. 52].
} 
del todo punto imposible pensar en una representación constitucional del pueblo, ya que tal cosa "no la conocen in praxis [en la práctica] las constituciones políticas antiguas, $y$, como puede esperarse, tampoco la han 'presentido' siquiera en su tragedia". ${ }^{30}$

Apolo, genio del principium individuationis, es el formador de Estados, pero un desarrollo incontrolado y desmedido del instinto político, de naturaleza apolínea, destruye el equilibrio entre ambas divinidades (tragedia), abortando la posibilidad y la existencia del arte. Asimismo, pensado muchas veces por Nietzsche como un fenómeno vinculado con el anterior, el crecimiento excesivo de lo lógico y el pensamiento filosófico, entendido como una degeneración de los impulsos apolíneos, acaba convirtiendo la tendencia apolínea en "crisálida" e, infiltrada en la tragedia, termina aniquilando lo dionisiaco, la tragedia y el arte mismo. ${ }^{31}$ Roma es, para Nietzsche, el ejemplo histórico de lo que ocurre cuando un pueblo se somete incondicionalmente a los instintos políticos: cae en una mundanización absoluta, en una entrega total a una voraz ambición de poder y de honor universales, ocupando todas las energías en la creación de un Imperio enorme y poderoso en el cual el arte ya no es posible, porque, convertido en un servidor más de la única finalidad existente, el crecimiento y la conservación del Imperio, pierde necesariamente el significado que le es propio. ${ }^{32}$

${ }^{30}$ Idem. En muchos lugares de los Póstumos de la época también alude Nietzsche, bajo diferentes aspectos, al antagonismo y la lucha entre el arte y la tragedia, y la politica. Por ejemplo: la transformación de la poesía en política debido al desmoronamiento del arte (F. Nietzsche, "Nachgelassene Fragmente", en op. cit., vol. VII, 1(7), p. 13); la destrucción del arte en la época de los sofistas, tiempo en el que, como en el presente de Nietzsche, ciencia y Estado van juntos (ibid., 3(11), p. 62); el combate a muerte entre el arte y el Estado platónico (ibid., 3(52), p. 75); la ausencia de cualquier vínculo del genio dionisiaco con el Estado, quien "no tiene nada que hacer con el Estado" (ibid., 9(130), p. 322. Traducción mía), etcétera.

31 F. Nietzsche, El nacimiento de la tragedia, pp. 121-122 ["Die Geburt der Tragödie", en op. cit., vol. I, p. 94].

${ }^{32}$ La tragedia es el "medicamento" que permite el equilibrio y la reconciliación de las potencias apolíneas y dionisiacas, "el compendio de todas las fuerzas curativas profilácticas, como el mediador soberano entre las cualidades más fuertes y de suyo más fatales del pueblo" (ibid., p. 167 [p. 134]), esa mezcla perfecta que caracteriza la superioridad de Grecia. Frente a los griegos, Roma e India son pueblos en los que la armonía apolíneadionisiaca se ha roto: en el primero, a causa de una degeneración política del instinto apolíneo (respecto a esto, véase F. Nietzsche, "Nachgelassene Fragmente", en op. cit., vol. VII, 7(37), p. 147 y 7(44), p. 149); en el segundo, a causa de una degeneración del instinto dionisiaco, el cual, al no poder ser transfigurado por la magia apolínea, acaba en el ensimismamiento extático del budismo o, lo que es lo mismo, en la negación del mundo (F. Nietzsche, El nacimiento de la tragedia, p. 166 ["Die Geburt der Tragödie", en op. cit., vol. I, p. 133]). 
Finalmente, el conflicto entre la tragedia y lo político se muestra en los efectos que la manifestación artística de lo dionisiaco produce en el individuo: el éxtasis y la embriaguez que afecta a la masa dionisiaca, al espectador que participa activamente en el espectáculo trágico, contiene un momento de quiebra del "yo" empírico y de la realidad cotidiana en que se desenvuelve el griego. Con ello se produce esa milagrosa reconciliación entre los hombres y entre el hombre y la naturaleza, esa restauración de la unidad de todas las cosas. La recomposición de Zagreo, el Dioniso niño despedazado por los Titanes, ese retorno a la Unidad que redime a la multiplicidad sufriente, expresado simbólicamente en la tragedia dionisiaca, tiene como consecuencia más inmediata el que: "el Estado y la sociedad y, en general, los abismos que separan a un hombre de otro dejan paso a un prepotente sentimiento de unidad, que retrotrae todas las cosas al corazón de la naturaleza". ${ }^{33}$

Ante el coro de sátiros, queda en suspenso la civilización, la mentira del hombre civilizado, surgiendo la verdad de la naturaleza, del hombre natural, de su ser eterno e inmutable; por lo tanto, también queda en suspenso el "hombre político", las relaciones sociales y las estructuras políticas de dominación.

En sí misma, pues, la experiencia trágica nada tiene que ver con la esfera pública, con la polis. Sin embargo, la tragedia, como insinúa Nietzsche en el aforismo que encabeza este texto, se encuentra vinculada necesariamente con una forma de vida humana, el hombre trágico, y con un tipo específico de organización política, el Estado trágico. Respecto a la tragedia hay que distinguir dos niveles: en primer lugar, su sentido metafísico, que en este caso también es estético; en segundo lugar, en el ámbito de la apariencia, las relaciones que mantiene con todos los órdenes de la existencia de esa forma de vida trágica. Es aquí, en la apariencia, donde la tragedia tiene también un sentido global y unitario, pues afecta todos los aspectos de la vida humana, siendo el centro que confiere unidad a todos ellos y organiza sus relaciones. La irrupción del fenómeno trágico tiene consecuencias en la totalidad de la realidad humana. Para Nietzsche, todas las partes que la forman están conectadas entre ellas mismas y con el todo; por consiguiente, cualquier modificación, mucho más si ésta es esencial, es decir, si afecta a la totalidad (como lo es la transformación trágica), tiene que incidir inevitablemente en cada una de las partes del todo y en sus relaciones jerárquicas. Que nada es ajeno a la reconciliación de las dos divinidades y que nada queda a salvo de la decadencia producida por el ocaso de la tragedia, está dicho por Nietzsche sin ninguna ambigüedad:

${ }^{33}$ Ibid., p. 167 [p. 56]. 
El ocaso de ésta [la tragedia] tuvo que parecernos provocado por el notable hecho de que estos dos instintos artísticos primordiales se disociaran: con este suceso concordaban una degeneración y una transformación del carácter del pueblo griego, invitándonos a una seria reflexión de cuán necesaria y estrechamente se hallan ligados en sus fundamentos el arte y el pueblo, el mito y la costumbre, la tragedia y el Estado. ${ }^{34}$

Afirmar el sentido unitario y global de la tragedia implica, entre otras muchas cosas, admitir una organización política y social que sea congruente y se corresponda con la magna obra de arte trágica; y también, dada la perspectiva holista y orgánica que adopta Nietzsche en su reflexión sobre la tragedia, la necesidad de un Estado trágico que haga posible la tragedia y la aparición del genio trágico, así como su continuidad en el tiempo. La política, en todas sus dimensiones, queda incorporada como instrumento imprescindible para la constitución del mundo trágico y como medio necesario para la consecución de la finalidad artística de la Voluntad. ${ }^{35}$ Paralelamente, la alianza entre Apolo y Dioniso ha de manifestarse en el conjunto de instituciones políticas, relaciones sociales y representaciones colectivas de la comunidad trágica. ${ }^{36}$ Por ello la tragedia, a pesar de que principalmente es la expresión simbólica del "misterio del Mundo", de que tiene que ser puesta en el centro del mundo, en el "vórtice del ser", ${ }^{37}$ y a pesar de que supone la redención más plena de la Voluntad sufriente y contradictoria, no se agota en la reproducción artística del juego divino de Zagreo. En la representación trágica, por el contrario, también entra en escena la política en tanto, y usando una frase afortunada de Vernant y Vidal-Naquet, "la ciudad se hace teatro", 38 pues el mito trágico,

${ }^{34}$ Ibid., pp. 181-182 [p. 147].

35 Numerosos son los textos en los que queda claramente establecida la función instrumental de la política, encontrándose los más destacados en el material póstumo: véase F. Nietzsche, "Nachgelassene Fragmente", en op. cit., vol. VII, 5(112), pp. 123 $124 ; 7(23)$, pp. $141-142 ; 7(25)$, p. $143 ; 7(40)$, p. $148 ; 7(121)$, pp. 168-169; 10(1), pp. $341-343 ; 11(1)$, p. $355 ; 29(73)$, p. 661; 30(8), pp. 733-734, y 32(62), p. 776.

36 "La relación de lo dionisiaco y lo apolíneo también tiene que reconocerse otra vez en cada forma de Estado, sobre todo en la exterioridad del Volkgeist" (ibid., 5(110), p. 123. Traducción mía). El nexo necesario entre la tragedia como manifestación artística suprema y una determinada organización estatal aparece, contemplado bajo diversos puntos de vista, en bastantes Póstumos de la época: véase ibid., 3(93), p. 85; 7(6), p. 138; 7(23), pp. 141-142, y 7(41), p. 148, etcétera. Estos y otros textos indican claramente la conexión necesaria entre la cultura (sea trágica, socrática o moderna) y las estructuras de dominación política (sea el Estado trágico, el platónico o el moderno).

37 Ibid., 11(1), p. 351. Traducción mía.

${ }^{38}$ Jean-Pierre Vernant y Pierre Vidal Naquet, Mito y tragedia en la Grecia arcaica. Madrid, Taurus, 1987, vol. I, p. 26. 
pasado el éxtasis de la vivencia dionisiaca en la representación, forma el ethos del ciudadano y nutre de vida a las instituciones políticas que permiten la liberación artística de las fuerzas dionisiacas.

El vínculo indisociable entre tragedia y política es mostrado de nuevo en el caso de Eurípides y en la muerte de la tragedia. Siendo para Nietzsche una máscara de Sócrates, un filósofo disfrazado de poeta, Eurípides, con esa postura arrogante y altanera hacia su público, derivada de su lucidez crítica y de la de su maestro, ${ }^{39}$ se entrega a la tarea de depurar el componente dionisiaco de la tragedia, para construir una nueva tragedia "sobre un arte, una moral y una consideración del mundo no-dionisiacos". ${ }^{40}$ Una nueva forma de vida invade la tragedia y acaba destruyéndola. Eurípides enseña al espectador cuando coloca al hombre cotidiano, con sus afanes, sus desvelos y sus metas, en la escena; le enseña a hablar, a calcular para conseguir sus propósitos, a llevar sus negocios, los trucos necesarios para salir bien parado en los procesos judiciales; le enseña, en definitiva, a ser un buen burgués, a sumarse lo más efectivamente posible al nuevo programa político de la Ilustración ateniense y a participar en las instituciones de una democracia consolidada, puesto que

La mediocridad burguesa, sobre la que Eurípides edificó todas sus esperanzas políticas, tomó ahora la palabra, después de que, hasta ese momento, quienes habían determinado el carácter del lenguaje habían sido, en la tragedia el semidiós, y en la comedia el sátiro borracho o el semihombre. ${ }^{41}$

Con la invasión del racionalismo socrático queda destruido el delicado equilibrio que mantenían Apolo y Dioniso en la tragedia ática, y también los "viejos tiempos", los tiempos de aquella tradición mítica que dio vida a una cultura, lo que Nietzsche consideraba el "ideal griego", y con él, sin duda, la polis trágica. La muerte de la tragedia y del mito trágico implica la muerte de las instituciones políticas y del tipo de sociedad que sobre ellos se había edificado. Sin embargo, también hay que decir que Eurípides no sólo es el portavoz de Sócrates: es el símbolo de una Atenas transformada, de una situación social y política que poco o nada tenía que ver con las tradiciones y las instituciones del pasado, de una polis decadente, resultado de unos procesos históricos cuyo origen se en-

${ }^{39}$ F. Nietzsche, El nacimiento de la tragedia, p. 105 ["Die Geburt der Tragödie", en op. cit., vol. I, p. 79].

${ }^{40}$ Ibid., p. 108 [p. 82].

${ }^{41}$ Ibid., p. 103 [p. 77]. Sobre el carácter "burgués" de Eurípides y la crisis de su tiempo, véase Werner Jaeger, Paideia. Trad. de Joaquín Xirau y Wenceslao Roces. México, FCE, 1978, pp. 303-324. 
cuentra, para Nietzsche, en los efectos devastadores que para el mundo griego tuvieron las guerras médicas. ${ }^{42}$ Eurípides, más que el portavoz de Sócrates, era el portavoz de los "nuevos tiempos", un perspicaz observador que elabora poéticamente la mentalidad, los problemas y las aspiraciones de los ciudadanos atenienses, y que les educa - no se puede olvidar en ningún momento la función educativa y formadora del teatro trágico dentro de la ciudad-Estado ateniense- para responder a las exigencias de la nueva realidad social y política de Atenas. ${ }^{43}$ La ciudad-Estado ateniense se convierte, después de haber sido creada la Liga de Delos, en Imperio, un Imperio marítimo y comercial que necesita el control de las rutas y la hegemonía sobre las ciudades -que en principio, y libremente, se asociaron a Atenas para defender a Grecia de la amenaza persa- para consolidar su poder y su democracia. ${ }^{44}$ Esta profunda transformación social y política, cuyo primer promotor fue Temístocles (el primero que supo ver, después de la guerra contra los persas, la necesidad de poseer una flota poderosa para conseguir la hegemonía política y económica en la Hélade), que culminaría con Efialtes y con Pericles, es el fermento histórico de la Ilustración ateniense y del racionalismo optimista de Sócrates. Su creación pasó necesariamente por la muerte del mito trágico y del mundo político y social que le correspondía. La política y la ciencia desbordan al arte poniéndolo a su servicio; la alianza Apolo-Dioniso se rompe, se expulsa a Dioniso, y Apolo se convierte en un pálido fantasma, en concepto y en "acción política". La mundanización atri-

${ }^{42}$ F. Nietzsche, "Nachgelassene Fragmente", en op. cit., vol. vII, 2(6), p. 46; vol. vIII, 6(27), pp. 108-109 y 6(30), p. 110.

${ }^{43}$ La idea de que Sócrates y Eurípides no son casos únicos, sino ejemplos eminentes de una situación general que para Nietzsche es de decadencia, está expuesta de manera explícita -refiriéndose sólo a Sócrates, pero igualmente aplicable a Eurípides- en Crepúsculo de los ídolos: "Pero Sócrates adivinó algo más. Vio lo que había detrás de sus aristocráticos atenienses; comprendió que su caso, la idiosincrasia de su caso, no era ya un caso excepcional. La misma especie de degeneración se estaba preparando silenciosamente en todas partes: la vieja Atenas caminaba hacia su final. Y Sócrates comprendió que todo el mundo tenía necesidad de él -de su remedio, de su cura, de su ardid personal para autoconservarse..." (F. Nietzsche, Crepúsculo de los ídolos. Introd., trad. y notas de Andrés Sánchez Pascual. Madrid, Alianza, 1973, p. 41 ["Götzen-Dämmerung", en Sämtliche Werke, vol. VI, p. 71]). La vieja autoridad tradicional y la aristocracia dominante son sustituidas por la dialéctica y por la toma del poder de la plebe. De nuevo aquí se nos muestra la correspondencia necesaria entre formas artísticas y formas de gobierno: autoridad tradicional (autoridad poética)-aristocracia, dialéctica-plebe (democracia). Sin esta situación generalizada de decadencia, sin esa anarquía de los instintos que se plasma en una nueva articulación política de la sociedad, Sócrates no hubiera sido otra cosa que un pobre "payaso", un oscuro sofista, y Eurípides, como dramaturgo, un fracasado, alguien repudiado por el espectador ateniense.

${ }^{44}$ Vid. C. M. Bowra, La Atenas de Pericles. Trad. de Alicia Yllera. Madrid, Alianza, 1979, pp. 84-96. 
buida por Nietzsche al Imperio romano tiene su antecedente en la mundanización del Imperio ateniense, proceso de efectos necesariamente disolventes para la tragedia y el mito. ${ }^{45}$

La totalidad de un mundo de la apariencia, caracterizado, frente a otros, como "obra de arte trágica", incluye, pues, todos los aspectos que conciernen a la vida humana: hombre trágico, Estado trágico y cultura trágica. En $E l$ nacimiento de la tragedia queda localizado el lugar que ocupa la esfera de lo público y el pensamiento relativo a ella: lugar secundario, porque se encuentra subordinado a la esfera de la cultura (Kultur), recibiendo de ella su justificación (en términos políticos: legitimación). La organización político-social de una comunidad es pensada por Nietzsche como un instrumento al servicio de unos fines que no son políticos, sino culturales y, en última instancia, artísticos: en la tragedia y el mito trágico encuentra su fundamento la teoría política, la praxis política y la estructura institucional que articula la vida social. Papel subordinado pero función absolutamente necesaria, pues la política aparece como un medio imprescindible para la conservación de la apariencia trágica. Aunque Apolo, divinidad que representa los instintos políticos, acabe hablando el lenguaje de Dioniso, éste necesita la voz diáfana del dios luminoso para que comience el espectáculo de su redención. El mito trágico, ese conjunto de representaciones que son una "imagen compendiada del mundo" y una "abreviatura de la apariencia", 46 es el fundamento de la cultura (trágica), aquello que aporta coherencia y unidad a las fuerzas apolíneas y el instrumento que, en virtud de su función educativa, forma el ethos del individuo, garantizando el reconocimiento a la autoridad tradicional y la obediencia a la ley del Estado, y constituyendo el conjunto de valores compartidos por la comunidad en los que el Estado se funda y a partir de los cuales crece. ${ }^{47}$ La política depende del mito, y el cambio de mitos es la causa de la transformación

45 Vattimo capta con toda exactitud este proceso y la interdependencia entre arte y política que existe para Nietzsche en el "caso Sócrates": vid. Gianni Vattimo, El sujeto y la máscara. Nietzsche y el problema de la liberación. Trad. de Jorge Binagui. Barcelona, Península, 1989, pp. 54-55.

${ }^{46}$ F. Nietzsche, El nacimiento de la tragedia, p. 179 ["Die Geburt der Tragödie", en op. cit., vol. I, p. 145].

47 "Mas toda cultura, si le falta el mito, pierde su fuerza natural sana y creadora: sólo un horizonte rodeado de mitos otorga cerramiento y unidad a un movimiento cultural entero. Sólo por el mito quedan salvadas todas las fuerzas de la fantasía y del sueño apolíneo de su andar vagando al azar. Las imágenes del mito tienen que ser los guardianes demónicos, presentes en todas partes sin ser notados, bajo cuya custodia crece el alma joven, y con cuyos signos se da el varón a sí mismo una interpretación de su vida y de sus luchas: y ni siquiera el Estado conoce leyes no escritas más poderosas que el fundamento mítico, el cual garantiza su conexión con la religión, su crecer a partir de representaciones míticas" (ibid., pp. 179-180 [p. 145]). 
de las estructuras de dominación política, ya que la autoridad política y el respeto a la ley se basan en la modelación del ethos por la paideia que el corpus mítico contiene. El Estado recibe su legitimidad de la religión, y ésta del mito, entendido como creación artística. ${ }^{48}$ La Ilustración ateniense, con su correlato necesario, la democracia, destruye el mundo mítico (la tragedia) y la forma aristocrática de gobierno; y en todo ello hay que ver una situación de decadencia, en la que progresivamente se pierde el vigor y la fortaleza de la antigua comunidad y se atrofian las energías corporales y psíquicas. ${ }^{49}$

Cultura, Estado, sociedad e individuo: todo se encuentra conectado en la totalidad trágica, cada esfera se relaciona con la otra consiguiendo una armonía precaria y perfecta, expresión de la alianza milagrosa de las dos divinidades. De cualquiera de las esferas, o de la alteración de sus relaciones jerárquicas, puede surgir el germen que contamine y acabe destruyendo el mundo trágico; en cualquier caso, el cambio de una mitología por otra mitología es una mutación radical que afecta a todos los aspectos de la vida del hombre. El ideario ilustrado ateniense y el ideario trágico de las épocas pasadas sólo pueden existir en sus mundos correspondientes. La política es una pieza más, con un sentido puramente secundario e instrumental, al servicio de la tragedia, un guardián sumiso y diligente que vela por su seguridad. En sí misma, la esfera pública no tiene ningún valor; como garante y soporte de la vida del mito trágico es una pieza esencial y necesaria. Esta definición normativa de la política es el contenido principal respecto al pensamiento político de $\mathrm{El}$ nacimiento de la tragedia; poco más hay en ella sobre estas cuestiones, pero este poco es mucho si consideramos que, aunque de una manera dispersa, ambigua y elusiva, responde a la pregunta sobre la naturaleza, las funciones y el valor de la política en la existencia del hombre. Responde, en definitiva, a una de las preguntas que ineludiblemente deben ser respondidas en esa disciplina llamada "filosofía política".

48 "Las representaciones religiosas son el seno materno de las políticas.

Las representaciones religiosas se originan en las artísticas.

El crecimiento de las representaciones artísticas como fuente de todo cambio religioso y estatal - mi tema.

Lo dionisiaco como madre de los misterios, de la tragedia, del pesimismo.

La revolución que realiza lo dionisiaco.

Quizá procede del mundo ético-político de la tragedia. El poeta trágico como maestro del pueblo: pero, ¿adónde apunta la doctrina de la tragedia?

Característica general del mito griego.

El Estado y el mito.

El arte y la religión" (F. Nietzsche, "Nachgelassene Fragmente", en op. cit., vol. VII, 9(61), p. 297. Traducción mía).

${ }^{49}$ F. Nietzsche, El nacimiento de la tragedia, p. 115 ["Die Geburt der Tragödie", en op. cit., vol. I, p. 88]. 